\title{
Ameliorating Episodic Memory Deficits in a Young Adult With Developmental (Congenital) Amnesia
}

\author{
Alice S.N. Kim, ${ }^{1,2}$ Foujan Minooei Saberi, ${ }^{1}$ Melody Wiseheart, ${ }^{1,3}$ AND R. Shayna Rosenbaum ${ }^{1,2,4}$ \\ ${ }^{1}$ Department of Psychology, York University, Toronto, Canada \\ ${ }^{2}$ Rotman Research Institute, Baycrest Health Sciences, Toronto, Canada \\ ${ }^{3}$ LaMarsh Centre for Child and Youth Research, York University, Toronto, Canada \\ ${ }^{4}$ Vision: Science to Applications (VISTA) Program, York University, Toronto, Canada
}

(Received December 5, 2017; Final Revision April 16, 2018; AcCEPted June 11, 2018)

\begin{abstract}
Objectives: Although the spacing effect has been investigated extensively in a variety of populations, few studies have focused on individuals with hippocampal amnesia and none, to our knowledge, have investigated differences in performance as a function of spacing schedule in these cases. In the current study, we investigated the benefit of expanding and equal-interval, compared to massed, spacing schedules in a developmental amnesic person, H.C., who shows congenitally based abnormal development of the hippocampal memory system. Methods: Given the possibility of plasticity and reorganization in the developing brain, we investigated whether H.C. would benefit more from an expanding versus equal-interval schedule using a continuous recognition paradigm, even though this task has been shown to recruit structures within the medial temporal lobe, including the hippocampus. Results: H.C. and matched controls both showed a clear spacing effect, although neither group benefited more from an equal-interval or expanding spacing schedule. Conclusions: The results of the current study show that the spacing effect is an effective and clinically meaningful memory intervention technique that may be applied to clinical conditions known to affect hippocampal function and episodic memory early in life. (JINS, 2018, 24, 1003-1012)
\end{abstract}

Keywords: Developmental amnesia, Hippocampal amnesia, Episodic memory, Spacing effect, Distributed practice, Continuous recognition paradigm, Spacing schedules

\section{INTRODUCTION}

Compromise to the hippocampal memory system very early in life has a marked effect on the development of episodic memory for personally experienced events, at times in the context of intact intellectual ability and at least some capacity for forming new semantic memories for general and personal factual information (Rosenbaum et al., 2011; VarghaKhadem et al., 1997, Vargha-Khadem, Salmond, Friston, Gadian, \& Mishkin, 2003). In the laboratory, this is reflected in impaired recollection of contextual information associated with studied items on tests of recall and recognition memory (Bindschaedler, Peter-Favre, Maeder, Hirsbrunner, \& Clarke, 2011; Brandt, Gardiner, Vargha-Khadem, Baddeley, \& Mishkin, 2008; Maguire, Vargha-Khadem, \& Mishkin,

Correspondence and reprint requests to: Alice S. N. Kim, Department of Psychology, York University, Toronto, Canada, E-mail: a_kim@yorku.ca
2001). The current study investigates if the spacing effect, a well-established method of ameliorating episodic memory impairment in adult populations, extends to a young adult with impaired episodic memory in relation to congenitally based abnormal development of the hippocampal system.

The hippocampus is highly vulnerable to a host of neurological conditions across the lifespan. In young children, hypoxic-ischemic events and temporal lobe epilepsy are among the most commonly known causes of significantly reduced hippocampal volume, believed to contribute to impaired episodic memory development (Cooper et al., 2015; Rosenbaum et al., 2014; Vargha-Khadem et al., 1997). More recent attention has been paid to other brain regions affected in developmental amnesia, primarily to highly interconnected diencephalic structures (Dzieciol et al., 2017), with a recent report in the case H.C. of absent mammillary bodies and abnormal rotation of the hippocampus bilaterally, suggestive of a congenital origin (Rosenbaum et al., 2014). Whether 
prenatal or postnatal, unlike individuals with adult-onset forms of hippocampal amnesia, developmental amnesics never acquired normal episodic memory before the onset of hippocampal volume loss. This may place them at a disadvantage in terms of opportunities to acquire learning strategies in the context of normal episodic memory. Alternatively, any disadvantage might be offset by the greater propensity for plasticity and reorganization when brain damage occurs early in life, as might have been the case in $\mathrm{H}$. C., who demonstrated intact and long-term benefits of distributed practice in word-list learning (Green, Weston, Wiseheart, \& Rosenbaum, 2014).

A relevant finding in the memory literature is the spacing effect, referring to the robust finding that long-term retention of information is enhanced when repeated study events are distributed in time compared to when they occur in immediate succession (Ebbinghaus 1885; Greene, 1989). The spacing effect has been replicated using an assortment of laboratory tests, including tests of free recall, cued recall, and recognition (Balota, Duchek, Sergent-Marshall, \& Roediger, 2006; Glenberg, 1976; Shaughnessy, Zimmerman, \& Underwood, 1972) in younger and older neurotypical adults, and in memory-impaired populations (Balota et al., 2006; Cermak, Verfaellie, Lanzoni, Mather, \& Chase, 1996; Goverover, Arango-Lasprilla, Hillary, Chiaravalloti, \& Deluca, 2009). Importantly, it has also been demonstrated at various developmental periods, from early infancy (RoveeCollier, Hayne, \& Colombo, 2000) and school age (Sobel, Cepeda, \& Kapler, 2011) to older adulthood (Balota et al., 2006).

Ease of administration and universality add to the appeal of distributed practice as a tool for memory enhancement, as it can be implemented in various rehabilitation settings for populations with memory disorders (Balota et al., 2006; Cermak et al., 1996; Green et al., 2014), and also contribute to the retention of information in educational programs (Kapler, Weston, \& Wiseheart, 2015; Pashler et al., 2007; Sobel et al., 2011) and in the workplace (Kim, Wong Kee You, Wiseheart, \& Rosenbaum, under review). Thus, efforts have turned to optimizing the spacing effect in a multitude of real-world applications, including improving memory in memory-impaired populations (Goverover, ArangoLasprilla, et al., 2009; Goverover, Hillary, Chiaravalloti, Arango-Lasprilla, \& DeLuca, 2009; Sohlberg, Ehlhardt, \& Kennedy, 2005). Although the benefit of distributed practice on memory has been investigated extensively in varied populations, only a few studies have focused on hippocampal amnesic patients. Those that do included individuals who developed amnesia as adults, and none to our knowledge investigated differences in performance as a function of spacing schedule (expanding vs. equal-interval), which might lead to different memory benefits (discussed below).

Cermak et al. (1996) investigated the effects of massed versus distributed practice on recognition and recall performance in a group of individuals with adult-onset amnesia due to Korsakoff's syndrome or encephalitis. Target words were repeated five times, with either five intervening items (lag 5 condition), or zero intervening items (lag 0 condition). Thus, these two conditions differed both in terms of the number of intervening items and the corresponding time delay associated with the presentation of the intervening items. The results indicated that amnesic patients benefited from spaced repetition as much as the healthy control participants on both the recognition and recall tasks. This experiment suggests that the spacing effect can be supported in amnesic individuals with medial temporal lobe (MTL) damage that includes the hippocampus.

This finding is at odds, however, with past functional magnetic resonance imaging (fMRI) research showing that the magnitude of activity and connectivity in the MTL was greater during repeated study of items after a long versus short delay, and that MTL connectivity following a long delay was predictive of subsequent paired-associate recall performance (Vilberg \& Davachi, 2013). Other studies have also shown reduced repetition suppression in MTL regions, including parahippocampal gyrus and both the left and right posterior hippocampus, when repetitions are spaced compared to massed in recognition (Xue et al., 2011) and continuous recognition (Brozinsky, Yonelinas, Kroll, \& Ranganath, 2005) paradigms.

In the context of implementing the spacing effect, an important question is how, or according to what schedule, should repeated study events be distributed? Distributed practice can be spaced out according to an equal-interval schedule, as used in the study by Cermak and colleagues (1996) described above, or an expanding schedule (Balota et al., 2006; Karpicke \& Roediger, 2007, 2010). An equalinterval schedule involves equally spread out study events, whereas an expanding spacing schedule involves gradually increasing the intervals between each subsequent exposure to the study item. These spacing conditions can be contrasted with a massed study schedule, in which repeated study events of a given item occur in immediate succession.

Mixed findings have been reported in the literature regarding whether an equal-interval schedule or expanding schedule is more beneficial for retention. Whereas some studies do not show a difference between the two types of spacing schedules (e.g., Balota et al., 2006; Carpenter \& DeLosh, 2005; Cull, 2000; Karpicke \& Bauernschmidt, 2011), other studies have demonstrated a larger benefit from expanding over equal-interval spacing schedules in specific contexts (Gerbier \& Keonig, 2012; Karpicke \& Roediger, 2007; Nakata, 2015), and yet other studies have indicated benefits of schedules where spacing was decreased with each subsequent study session (Küpper-Tetzel, Kapler, \& Wiseheart, 2014). However, no known studies have examined whether people with developmental amnesia benefit more from an expanding relative to an equal-interval spacing schedule. Moreover, to our knowledge, only one study has even investigated the spacing effect in a developmental amnesic person (Green et al., 2014, who studied H.C.).

In the first of two experiments, Green and colleagues (2014) assessed the impact of distributed practice on H.C.'s memory performance in a free recall, verbal learning 
paradigm. The results showed that the largest spacing lag (24 intervening items between repeated study events) increased H.C.'s recall performance by $20 \%$ compared to the massed (lag 0 ) condition. The second experiment used a multi-day, paired-associate, learning-to-criterion, verbal learning spacing paradigm, in which memory was assessed after 1 week. H.C. performed $40 \%$ better in the spaced review, compared to the massed, condition. However, H.C. took four times as many trials to reach criterion compared with controls, suggesting that her spacing effect was achieved via abnormal means and might not be reproduced at this magnitude without intensive training conditions. That H.C.'s training was labourious compared to controls on the paired-associate, learning-to-criterion task reported in Green et al. (2014) may relate to the abovementiond finding that the spacing effect is associated with MTL activity in the context of pairedassociate recall (Vilberg \& Davachi, 2013).

The aim of the present study was to further investigate the spacing effect in developmental amnesia by continuing to profile the impact spacing has on H.C.'s memory performance. To complement the previous investigation on the spacing effect in H.C. (Green et al., 2014), the present study investigated whether an expanding or equal-interval spacing schedule would result in better memory performance in H.C. A second aim of the present study was to determine the impact of spacing, if any, on H.C.'s memory performance in the context of a continuous recognition paradigm. Although H.C. has benefited from spacing on tests of free recall and paired-associate recall, fMRI evidence of hippocampal activation associated with the spacing effect in continuous recognition (Brozinsky et al., 2005) suggests that she might not benefit in this instance. Given the potential of the spacing effect as an intervention technique for individuals with compromised episodic memory in relation to hippocampal system compromise, it is important to know when it will be effective.

\section{METHODS}

\section{Design}

The study had a two (group: H.C. vs. controls) $\times$ three (spacing schedule: massed, equal-interval, expanding) mixed factorial design. Both groups were presented with English nouns, as described further below, and target words were presented six times according to one of the three spacing schedules, the independent variable. The spacing schedules were adapted from a previous study by Balota et al. (2006) that investigated the spacing effect in healthy young and older adults, as well as individuals with dementia of the Alzheimer's type. In the study by Balota et al., targets in each of the spacing conditions (massed, equal-interval, and expanding) were initially presented three times in immediate succession to help ensure that all participant groups successfully encode the words. Then, after the third presentation of the target, the spacing schedules differed. Here we used the same approach of presenting targets three times in immediate succession in each of the spacing conditions to help ensure that H.C. and control participants successfully encoded the words.

Following Balota et al., a learning-to-criterion requirement was not implemented in the present study. After the third presentation of the target, the spacing schedules differed. In the massed schedule, the target was presented three more times in immediate succession. Thus, the first presentation of the target was followed by five massed repetitions (massed: 0-0-0-0-0). The equal-interval schedule consisted of the initial presentation of the target, followed by two massed repetitions, and then three equally spaced repetitions with three intervening events (equal interval: 0-0-3-3-3). The expanded schedule consisted of the initial presentation of the target, followed by two massed repetitions, and then three expanding repetitions with one, three, and five intervening events (expanded: 0-0-1-3-5). The dependent variable was participants' free recall and recognition performance, as described further below.

\section{Materials}

The word pool used in the current study consisted of 175 onesyllable nouns taken from the MRC Psycholinguistic Database (Coltheart, 1981), with imageability and Kucera-Francis frequency (Kucera \& Francis, 1967) ratings of 432 to 667 and 1 to 967 , respectively. The nouns were randomly assigned to one of five lists, with each list having a total of 35 unique words. In each list, 8 words served as primacy buffers and 8 words served as recency buffers. Each study list consisted of 9 target words: 3 target words were presented under each of the 3 spacing schedules. Targets were counterbalanced across participants. The remaining 10 words in the list served as filler words included throughout the study list to ensure the proper spacing of the items.

\section{Participants}

H.C. is a right-handed woman who was 27 years old at the time of testing. She was born prematurely in gestational week 32 and was assumed to have experienced hypoxia soon after birth (Olsen et al., 2013; Rosenbaum et al., 2014), resulting in impaired episodic memory that was first noted when she was 4 years of age. Analysis of MRI scans taken in 2012 indicates relatively focal changes to the hippocampus and structures closely connected to it (Olsen et al., 2013), which has been found in other cases of developmental amnesia (Dzieciol et al., 2017). H.C.'s hippocampal volume is reduced by $30 \%$ bilaterally, and this reduction is generally consistent across subfields. However, a more recent study suggests that H.C.'s memory impairment and neuroanatomical findings may be congenital in origin. A detailed examination of H.C.'s hippocampal memory system displayed agenesis of the mammillary bodies, rerouting of the fornices, and hippocampal malrotation (Rosenbaum et al., 2014). The 
hippocampal malrotation entails incomplete infolding of the hippocampus, appearing abnormally rounded in shape. The absence of mammillary bodies is significant because the mammillary bodies begin to form in fetal development at 9-10 weeks, and hippocampal rotation begins at 13 weeks (Rosenbaum et al., 2014). H.C. has been studied extensively and her memory impairments are well-documented. Her neuropsychological profile is displayed in Table 1.

H.C. demonstrates impaired episodic recollection and intact familiarity processes (Rosenbaum et al., 2011), and has difficulty remembering personal and public events. Unlike control participants and individuals with Korsakoff syndrome in whom mammillary bodies are reduced (Cermak, Butters, \& Moreines, 1974), H.C.'s anterograde recognition memory performance does not appear to benefit from semantic encoding of verbal study material. H.C.'s memory performance does, however, benefit from distributed, compared to massed, repetition (Green et al., 2014), as described above. She has also learned to compensate for her impaired episodic memory by using devices to help her remember events and goals. H.C. completed high school and 2 years of college, and has successfully held several jobs. In the present study, H.C.'s performance was compared to that of 10 healthy control participants who were matched to her in terms of age and education ( 7 females; mean age, 25.2 years; $S D$, 1.13; range, 24-27 years; mean education, 15.2 years; $S D$, 1.13, range; 13-16 years). Participants were fluent in English and had no known history of psychiatric or neurological illness. All participants gave written informed consent and received monetary compensation for their participation, as approved by the Baycrest and York University ethics committees.

\section{Procedure}

Each participant took part in one experimental session. Throughout the session, participants were seated in front of an LCD monitor connected to a computer. The experimenter was seated near the participant in a position where they were able see the LCD monitor and use the keyboard to record the participants' verbal responses. At the start of the session, both written and verbal instructions were given for the experimental task, and participants completed a practice run to ensure that they understood the task before starting the experiment.

For H.C., the session consisted of five study/test cycles, which each corresponded to one of the five word lists. To avoid ceiling effects in controls and increase the difficulty of this task, the session consisted of one study/test cycle, which included all five words lists. Each study/test cycle consisted of a study phase and test phase. During the study phase, participants performed a continuous recognition task, with stimuli presented using E-Prime software (Version 1.1, www.neurobs. com). Words were presented sequentially in black uppercase letters on a white background for $4 \mathrm{~s}$. After the presentation of each word, a question screen was presented with the statement,
Table 1. Neuropsychological profile of H.C.

\begin{tabular}{|c|c|c|}
\hline Test & $\begin{array}{l}\text { Raw } \\
\text { score }\end{array}$ & Normed score \\
\hline \multicolumn{3}{|l|}{ Intellectual function } \\
\hline WASI & & Percentile \\
\hline Verbal IQ & 104 & 61 \\
\hline Performance IQ & 106 & 66 \\
\hline Full Scale IQ & 106 & 66 \\
\hline AM-NART & & Standard score \\
\hline Total correct & 27 & $\begin{array}{l}101.28 \text { (estimated } \\
\text { FSIQ) }\end{array}$ \\
\hline WAIS-III & & Scaled score \\
\hline Arithmetic & 10 & 8 \\
\hline Information & 19 & 12 \\
\hline Language & & Percentile \\
\hline Boston Naming Test ${ }^{\mathrm{a}}$ & 58 & $77-79$ \\
\hline Semantic Fluency (animals) & 32 & $>90$ \\
\hline Phonemic Fluency (FAS) ${ }^{\mathrm{b}}$ & 53 & $70-80$ \\
\hline WASI & & T-score \\
\hline Vocabulary & 58 & 55 \\
\hline \multicolumn{3}{|l|}{ Anterograde memory } \\
\hline WMS-III & & Scaled score \\
\hline Logical Memory I & 27 & 4 \\
\hline Logical Memory II & 3 & 1 \\
\hline \multicolumn{3}{|l|}{ II } \\
\hline total trials $1-5$ & 44 & 38 (T-score) \\
\hline short delay free recall & 0 & -4 \\
\hline short delay cued recall & 5 & -3.5 \\
\hline long delay free recall & 3 & -3 \\
\hline long delay cued recall & 4 & -3.5 \\
\hline Recognition & 13 & -2 \\
\hline Rey-Osterreith complex figure ${ }^{c}$ & & T-score \\
\hline immediate recall & 4 & $<20$ \\
\hline delayed recall & 3 & $<20$ \\
\hline delayed recognition & 17 & 22 \\
\hline \multicolumn{3}{|l|}{ Processing speed } \\
\hline WAIS-III & & Scaled score \\
\hline Digit Symbol & 96 & 13 \\
\hline Symbol Search & 45 & 14 \\
\hline Visuospatial function & & Percentile \\
\hline Judgement of Line Orientation & 24 & 56 \\
\hline Benton Facial Recognition & 45 & $33-59$ \\
\hline $\begin{array}{l}\text { Rey-Osterrieth Complex Figure } \\
- \text { Copy }^{c}\end{array}$ & 33 & $>16$ \\
\hline WASI & & T-score \\
\hline Block Design & 52 & 54 \\
\hline \multicolumn{3}{|l|}{ Attention and executive function } \\
\hline Stroop $^{\mathrm{d}}$ & & $Z$-score \\
\hline Word full (s) & 45 & 3.65 \\
\hline Color full (s) & 48 & -0.03 \\
\hline Interference full (s) & 80 & -0.57 \\
\hline Trail Making Test ${ }^{\mathrm{a}}$ & & $Z$-score \\
\hline Part A (s) & 34 & 0.69 \\
\hline Part B (s) & 55 & -0.23 \\
\hline WASI & & T-score \\
\hline Similarities & 35 & 50 \\
\hline Matrix Reasoning & 29 & 55 \\
\hline WAIS-III & & Scaled score \\
\hline Digit span forward & 10 & \\
\hline
\end{tabular}


Table 1. (Continued)

\begin{tabular}{lcc}
\hline \multicolumn{1}{l}{ Test } & $\begin{array}{c}\text { Raw } \\
\text { score }\end{array}$ & Normed score \\
\hline \multicolumn{1}{c}{ Digit span backward } & 5 & \\
$\quad$ Digit span total & 15 & 8 \\
Wisconsin Card Sorting Task & & T-score \\
$\quad$ Categories & & 57 \\
$\quad$ Perseverative errors & 10 & \\
\hline \hline
\end{tabular}

Note. AM-NART, American National Adult Reading Test; WASI, Wechsler Abbreviated Scale of Intelligence; WAIS-III, Wechsler Adult Intelligence Scale-III. Additional results of neuropsychological testing reported in Rosenbaum et al. (2011), Hurley et al. (2012), and Rabin et al. (2012).

${ }^{\text {a }}$ Spreen \& Strauss (1998).

${ }^{\mathrm{b}}$ Tombaugh, Kozak, \& Rees (1996)

'Meyers \& Meyers (1996).

${ }^{\mathrm{d}}$ In-house unpublished normative data.

${ }^{\mathrm{e}}$ Heaton et al. (1993).

"Has this word previously been shown?", in black font on a white background. This question was presented for $15 \mathrm{~s}$, followed by an instruction to verbally state with a "yes" or "no" response if the word had been seen previously. The experimenter then entered " $Y$ " for a "yes" response and " $N$ " for a "no" response using the keyboard. A black fixation cross of $0.5 \mathrm{~s}$ was placed in between all words and question screens. Figure 1 depicts the temporal sequence of the task.

During the test phase, participants were first tested on free recall and given the equivalent of $1 \mathrm{~min}$ per study list to recall as many words as they could from the study list. Thus, whereas H.C. was given 1 min during each of the five study/ test cycles, controls were given $5 \mathrm{~min}$ for the 1 study/test cycle they completed. Next, participants were given a recognition test, which required them to judge whether they had seen the word during the study phase. Similar to the study phase, words were presented sequentially in black uppercase letters on a white background for $4 \mathrm{~s}$. After the presentation of each word, a question screen was presented with the statement, "Has this word previously been shown?", in black on a white background. This question was presented for $15 \mathrm{~s}$, followed by an instruction to verbally state with a "yes" or "no" response if the word had been seen previously. The experimenter then entered "Y" for a "yes" response and " $N$ " for a "no" response using the keyboard. For each of H.C.'s 5 study/test cycles, the words presented during the recognition test consisted of the 9 targets in the corresponding list and six distractors. Controls were tested on recognition using the same overall number of targets and distractors presented to $\mathrm{H}$. C.: 45 targets and 30 distractors. The entire experiment lasted approximately $60 \mathrm{~min}$.

\section{Analyses}

Participants' free recall performance was scored according to the proportion of words that were correctly recalled at test. Recognition performance was assessed by deriving hit rate minus false alarm rate scores. The recall and recognition data were analyzed separately using repeated-measures analyses of variance (ANOVAs), with spacing schedule as the sole factor. A post hoc modified $t$ test, designed for testing a single case against a control group of small to moderate size (Crawford \& Howell, 1998), was then used to compare H. C.'s memory performance to matched controls.

\section{RESULTS}

\section{Free Recall}

H.C.'s free recall performance (proportion correct) was at floor, as seen in Figure 2. She recalled one, two, and zero

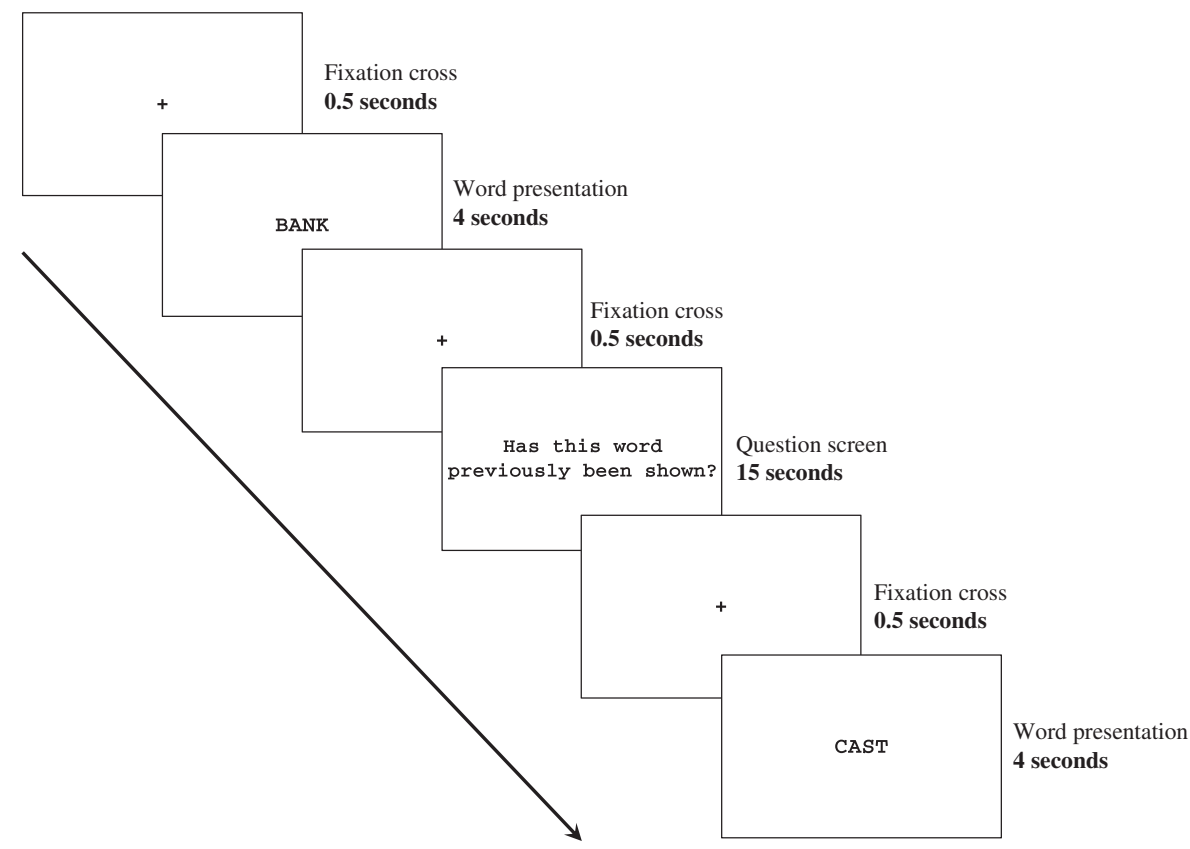

Fig. 1. Temporal sequence of the study phase and the recognition memory test. 


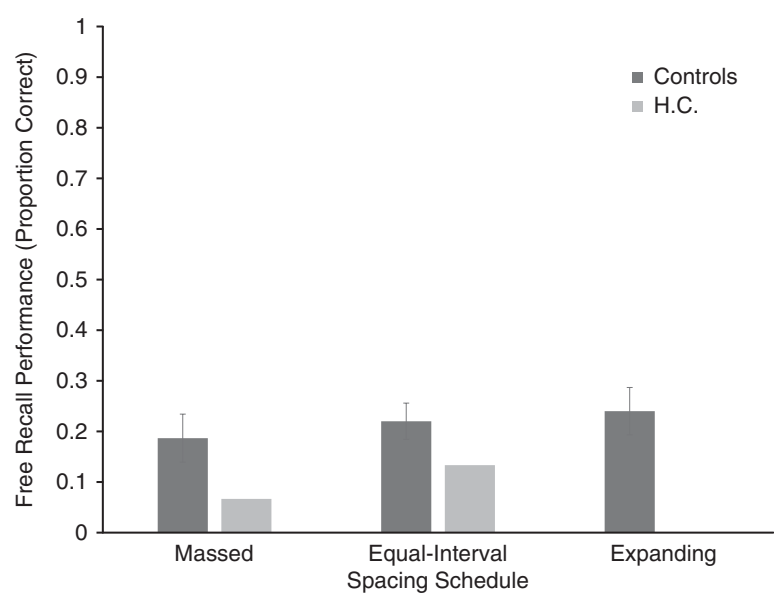

Fig. 2. Free recall performance (proportion correct) for $\mathrm{HC}$ and controls. Error bars $=$ standard error.

target words from the massed, equal-interval, and expanding spacing schedules, respectively. Since H.C. demonstrated floor effects for free recall, her data were not submitted to any statistical analyses. Free recall performance for healthy control participants is also presented in Figure 2, which shows that recall was highest for the expanding spacing schedule $(M=.240 ; S D=.147)$ followed by the equal interval $(M=.220 ; \quad S D=.114)$ and massed spacing $(M=.187$; $S D=.151)$ schedules, respectively. However, the results of a repeated-measures ANOVA conducted on the control data did not reveal a significant effect of spacing $[F(2,18)=.787$; $p=.47]$.

\section{Recognition}

Figure 3 displays corrected recognition scores (hit rate - false alarm rate) for H.C. and healthy control participants. Recognition performance for the healthy controls was lowest in the massed spacing schedule $(M=.610 ; S D=.179)$, followed by the equal-interval $(M=.703 ; S D=.193)$ and expanding $(M=.710 ; S D=.166)$ spacing schedules, respectively. The results of the repeated-measures ANOVA conducted on the control data indicated a significant effect of spacing $\left[F(2,18)=5.999 ; \quad p=.01 ; \quad \eta_{\mathrm{p}}^{2}=.4\right]$. Bonferronicorrected post hoc tests showed a significant difference between massed and equal-interval schedules $(p=.029)$, and between massed and expanding schedules $(p=.035)$. A significant difference was not detected between equal-interval and expanding conditions $(p=1)$.

H.C.'s recognition performance was lowest in the massed spacing schedule, followed by the expanding and equalinterval spacing schedules, respectively. Although the results shown in Figure 3 may seem suggestive of disproportionate differences between H.C. and the control group in the massed spacing schedule compared to the two spacing schedules, the results of the modified Crawford $t$ test did not reveal any significant differences between H.C.'s recognition performance compared to that of controls across the three spacing schedules [massed $t(10)=1.123 ; p=.288$; equal-interval

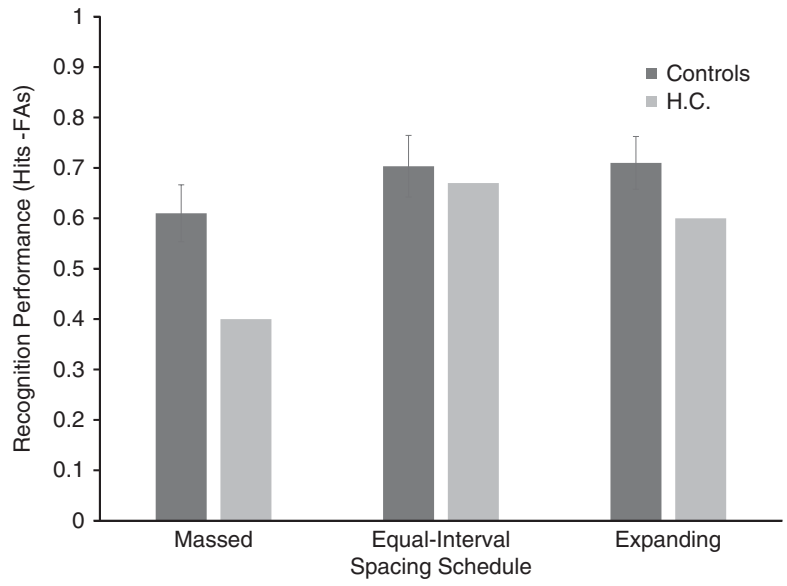

Fig. 3. Corrected recognition performance (hit rate - false alarm rate) for $\mathrm{HC}$ and controls. Error bars = standard error

$t(10)=0.164 ; \quad p=.872 ; \quad$ and expanding $t(10)=0.633$; $p=.541]$.

\section{DISCUSSION}

The present study provides evidence of a spacing effect in the developmental amnesic person H.C., whereby recognition of studied words benefited when they were repeated with intervening words between repetitions (spaced) compared to when they were repeated in immediate succession (massed). These results are in line with and extend those reported in previous studies (Balota et al., 2006; Green et al., 2014) by demonstrating a spacing effect in H.C. using a continuous recognition paradigm, which is associated in fMRI with reduced repetition suppression within the hippocampus/MTL when repetitions are spaced compared to massed (Brozinsky et al., 2005). Although a clear spacing effect was seen in both healthy controls and a developmental amnesic person, neither showed a difference in benefit between equal-interval and expanding schedules, which is in line with past studies using similar study designs (Balota et al., 2006; Cull, 2000; Carpenter \& DeLosh, 2005; Logan \& Balota, 2008).

However, there is some evidence in the literature suggesting that the preferred spacing schedule (expanding vs. equal-interval) may vary based on retention interval (Karpicke \& Roediger, 2007; Logan \& Balota, 2008), study task (Gerbier \& Koenig, 2012; but also see Cull, 2000), and the amount of spacing separating early retrieval attempts, whereby expanded retrieval benefits are more likely to occur for nonsystematic expansion (e.g., 0-1-6-8-10) compared to systematic expansion (e.g., 0-2-4-6-8) when there is an increased likelihood of successful early retrieval events (Maddox, Balota, Coane, \& Duchek, 2011). Future research should continue to investigate whether these factors impact the benefit of distributed practice on memory in both amnesic and neurotypical populations.

The finding that H.C., and amnesic participants in general, demonstrate a spacing effect lends itself to interesting discussion of one of the leading account of this effect: the study- 
phase retrieval hypothesis. According to this hypothesis, repeated occurrences of a target automatically serve as retrieval cues for its previous occurrence, which is assumed to be critical for repeated practice to be effective (Raaijmakers, 2003, Thios \& D'Agostino, 1976). The benefit of repetition is elevated further when retrieval is successful in spaced conditions, because the spacing between repetitions places greater demands on retrieval processes compared to when the repetitions are massed. This desirable retrieval difficulty is assumed to benefit the memory trace more compared to when retrieval is easier, partly because it is hypothesized to slow the rate of forgetting (Rovee-Collier, 1995; Toppino \& Gerbier, 2014). Thus, according to the study-phase retrieval account, one might expect that hippocampal amnesic participants would benefit less than controls from study-phase retrieval, due to retrieval difficulty demonstrated by the former group. However, as discussed further below, it is possible that spaced repetition engages strategic retrieval processes that may support longer-lasting representations in memory and are upheld by the prefrontal cortex (PFC), which is intact in these patients.

The spacing effect demonstrated by H.C. in the present study may have been supported by intact MTL regions. Whereas past studies have shown perirhinal cortex to be engaged during item recognition, the hippocampus, fornix, and mammillary bodies have been implicated in recall (Aggleton \& Brown, 1999, Tsivilis et al., 2008). Despite the absence of H.C.'s mammilliary bodies and anterior fornices as well as atrophy of the anterior thalamic nuclei bilaterally and hippocampal malrotation/volume loss, her perirhinal cortex, parahippocmpal cortex, and entorhinal cortex remain intact (Olsen et al., 2013). Thus, it is not completely surprising that H.C.'s free recall performance was at floor, whereas her recognition performance was comparable to that of control participants across each of the spacing conditions (massed, expanding, equal-interval). The results of the present study aligns with the study-phase retrieval hypothesis, in that in contexts that are more conducive to H.C.'s successful retrieval (e.g., recognition tests), spaced versus massed repetitions are more beneficial for subsequent memory performance.

Interestingly, however, H.C. previously showed a spacing effect in the context of a free recall paradigm (Green et al., 2014), which may seem inconsistent with H.C.'s floor performance on free recall in the present study. This apparent discrepancy may be due to differences in the paradigms used in the two studies. Green and colleagues (2014) had participants encode a series of words in a list, allotting $1.5 \mathrm{~s}$ of study time per word. In the current study, participants encoded a series of words in a list with a time allowance of $4 \mathrm{~s}$ per word. Additionally, immediately after the presentation of each word, participants judged whether they had already seen the word in the list. Thus, the amount of time that transpired by the end of a study list, as well as the encoding task itself, differed across both studies. Another major difference between the two studies was the used spacing schedules: whereas the current study used massed, equal-interval, and expanding spacing schedules, with each target repeated five times, Green et al. (2014) used lags of 0, 1, 6, and 24 intervening items, with each target presented twice under one of the four lag conditions. Together, these paradigm differences may help account for H.C.'s seemingly inconsistent free recall performance across the two studies.

One might also wonder whether testing participants on free recall before recognition impacted the results of the latter test. The relation between recall and recognition has been studied extensively, and although it was once believed that recognition is automatic and independent of recall processes, past studies have shown that recall and recognition are related and associated with comparable retrieval processes in healthy and amnesic populations (Haist, Shimamura, \& Squire, 1992; Tulving \& Thomson, 1971). However, these findings should be considered in the context of the abovementioned findings that specific brain structures have been differentially associated with recall and recognition (Aggleton \& Brown, 1999, Tsivilis et al., 2008).

Moreover, the phenomenon of "recognition failure of recallable words" (Tulving \& Thomson, 1973) demonstrates that it is possible for successful recall to be paired with unsuccessful recognition of a target item. Thus, although recall and recognition seem to be associated with comparable retrieval processes, the neural findings, combined with demonstrated dissociations between recall and recognition performance, suggest that these forms of retrieval do not overlap entirely. It is not clear whether and to what extent the preceding free recall test impacted the results of the recognition test in the present study, particularly in light of the finding that H.C. showed floor effects for recall.

Another explanation for the spacing effect demonstrated by H.C. could be related to neocortical compensatory mechanisms, through which H.C. achieved similar levels of recognition performance as control participants but via alternative means. Past fMRI work has shown that Jon, another person with developmental amnesia who experienced $50 \%$ volume loss in his hippocampi, demonstrated increased activity in the same brain regions as control participants during a retrieval task, in addition to regions that were not activated in the healthy control participants (Maguire et al., 2001). Similarly, H.C. has also demonstrated activity in several extra-hippocampal brain regions to a greater extent than that found in control participants on tasks that required remembering and imagining (Rabin, Olsen, Gilboa, Buchsbaum, \& Rosenbaum, 2016). However, functional connectivity between these extra-hippocampal and hippocampal regions did not differ between H.C. and control participants. Thus, it is difficult to draw conclusions about compensatory mechanisms.

One could speculate, however, on the importance of cognitive control processes, such as those relating to strategic retrieval in the spacing effect. Of interest, past fMRI studies have shown that reduced repetition suppression in the left PFC leads to better subsequent memory performance (Callan \& Schweighofer, 2010; Wagner, Maril, \& Schacter, 2000). Along these lines, it could also be the case that the spacing 
effect that Cermak and colleagues (1996) showed in adultonset amnesics was supported by prefrontally mediated strategic retrieval processes that remained intact in these patients. Although speculative, it is possible that MTL structures work together with the PFC to support the spacing effect, and that the PFC supports the effect when hippocampal function is compromised.

A general theoretical framework, referred to as Working With Memory (WWM), describes the contribution of the frontal lobes to strategic memory processing (Moscovitch, 1992; Moscovitch \& Winocur, 1992). Generally, the frontal lobes are thought to enrich the memory trace and facilitate memory processes. For example, there is evidence that the frontal lobes keep track of time with respect to temporal order effects (McAndrews \& Milner, 1991; Milner, Petrides, \& Smith, 1985; Moscovitch \& Melo, 1997) and enahnce information with semantic organization during encoding (McAndrews \& Milner, 1991). Additionally, the dorsolateral PFC has been implicated in setting the goals of the retrieval task and beginning the retrieval search process, thereby establishing a retrieval mode (Lepage, Ghaffar, Nyberg, \& Tulving, 2000; Rugg \&Wilding, 2000) by preparing an individual to engage in retrieval. Moreover, the posterior ventromedial PFC and frontal pole are thought to signal acceptance and rejection, respectfully, of a signal resulting from an activated memory trace based on an intuitive "felt rightness" (Moscovitch \& Winocur, 2002). Although interactions between MTL and PFC cannot be determined based on a behavioural study of a single case, it is an important direction for future patient research.

The present study provides additional insight into the spacing effect in H.C., a young adult with developmental amnesia. Along with the many benefits afforded by case studies (for discussion see Rosenbaum, Gilboa, \& Moscovitch, 2014), there are additional drawbacks, including limitations in terms of the generalizability of the results due to the small sample size. Another potential limitation of the present study is the use of the modified Crawford $t$ test to compare H.C.'s performance to that of controls, as it has been shown to be conservative (Crawford \& Howell, 1998), making it more prone to Type II errors. An alternative approach would have been to conduct a 2 (group: H.C., controls) $\times 3$ (spacing condition) between-within repeated measures ANOVA using H.C.'s recognition scores from each of the five lists she completed to calculate a mean and variance values. Alternatively, H.C.'s overall mean score could have been paired with the variance of the control group to conduct the ANOVA. However, this would lead to the limitation of assuming that H.C.'s variance is equivalent to that of the control group. Yet another approach, described in Green et al. (2014), is to resample H.C.'s data to create an artificial group. The corresponding limitation, however, would be the lack of independent observations. Future research should be conducted to test whether the findings of the present study are replicable in other (adult) developmental amnesics.

\section{ACKNOWLEDGMENTS}

We are grateful to H.C. and her family for their continued contributions to memory research. This research was supported by grants from the Canadian Partnership for Stroke Recovery and National Sciences and Engineering Research Council of Canada to R.S.R. and a fellowship from the Canadian Partnership for Stroke Recovery to A.S.N.K. The authors declare no conflicts of interest.

\section{REFERENCES}

Aggleton, J.P., \& Brown, M.W. (1999). Episodic memory, amnesia, and the hippocampal-anterior thalamic axis. Behavioral and Brain Sciences, 22(3), 425-444. http://doi.org/10.1017/ S0140525X99002034

Balota, D., Duchek, J., Sergent-Marshall, S., \& Roediger, H. (2006). Does expanded retrieval produce benefits over equal-interval spacing? Explorations of spacing effects in healthy aging and early stage Alzheimer's disease. Psychology and Aging, 19-31. doi: 10.1037/0882-7974.21.1.19

Bindschaedler, C., Peter-Favre, C., Maeder, P., Hirsbrunner, T., \& Clarke, S. (2011). Growing up with bilateral hippocampal atrophy: From childhood to teenage. Cortex, 47(8), 931-944. https://doi.org/10.1016/j.cortex.2010.09.005

Brandt, K.R., Gardiner, J.M., Vargha-Khadem, F., Baddeley, A.D., \& Mishkin, M. (2008). Impairment of recollection but not familiarity in a case of developmental amnesia. Neurocase, 15(1), 60-65. http:// doi.org/http://dx.doi.org/10.1080/1355479080261302

Brozinsky, C.J., Yonelinas, A.P., Kroll, N.E., \& Ranganath, C. (2005). Lag-sensitive repetition suppression effects in the anterior parahippocampal gyrus. Hippocampus, 15(5), 557-561. doi: 10.1002/hipo.20087

Callan, D. E., \& Schweighofer, N. (2010). Neural correlates of the spacing effect in explicit verbal semantic encoding support the deficient-processing theory. Human brain mapping, 31(4), 645659. DOI: $10.1002 / \mathrm{hbm} .20894$.

Carpenter, S.K., \& DeLosh, E.L. (2005). Application of the testing and spacing effects to name learning. Applied Cognitive Psychology, 19(5), 619-636. http://doi.org/10.1002/acp.1101

Cermak, L.S., Butters, N., \& Moreines, J. (1974). Some analyses of the verbal encoding deficit of alcoholic Korsakoff patients. Brain and Language, 1(2), 141-150. https://doi.org/10.1016/0093934X(74)90030-3

Cermak, L.S., Verfaellie, M., Lanzoni, S., Mather, M., \& Chase, K.A. (1996). Effect of spaced repetitions on amnesia patients' recall and recognition performance. Neuropsychology, 10(2), 219-227. http://doi.org/10.1037//0894-4105.10.2.219

Coltheart, M. (1981). The MRC psycholinguistic database. The Quarterly Journal of Experimental Psychology, 33(4), 497-505. https://doi.org/10.1080/14640748108400805

Cooper, J.M., Gadian, D.G., Jentschke, S., Goldman, A., Munoz, M., Pitts, G., ... Vargha-Khadem, F. (2015). Neonatal hypoxia, hippocampal atrophy, and memory impairment: Evidence of a causal sequence. Cerebral Cortex, 25(6), 1469-1476. https://doi. org/10.1093/cercor/bht332

Crawford, J.R., \& Howell, D.C. (1998). Comparing an Individual's Test Score Against Norms Derived from Small Samples. The Clinical Neuropsychologist, 12(4), 482-486. DOI: 10.1076/ clin.12.4.482.7241

Cull, W.L. (2000). Untangling the benefits of multiple study opportunities and repeated testing for cued recall. Applied 
Cognitive Psychology, 14(3), 215-235. doi: 10.1002/(SICI)10990720(200005/06)14:3 < 215::AID-ACP640 > 3.0.CO;2-1

Dzieciol, A.M., Bachevalier, J., Saleem, K.S., Gadian, D.G., Saunders, R., Chong, W.K.K., ... Vargha-Khadem, F. (2017). Hippocampal and diencephalic pathology in developmental amnesia. Cortex, 86, 33-44. http://doi.org/10.1016/j. cortex.2016.09.016

Ebbinghaus, H.Uber das Gedachtnis. Dover; New York1885.

Gerbier, E., \& Koenig, O. (2012). Influence of multiple-day temporal distribution of repetitions on memory: A comparison of uniform, expanding, and contracting schedules. The Quarterly Journal of Experimental Psychology, 65(3), 514-525. http://dx. doi.org/10.1080/17470218.2011.600806

Glenberg, A. (1976). Influences of retrieval processes on the spacing effect in free recall. Journal of Experimental Psychology: Human Learning \& Memory, 3, 282-294. http://dx.doi.org/10.1037/0278-7393.3.3.282

Goverover, Y., Arango-Lasprilla, J., Hillary, F., Chiaravalloti, N., \& Deluca, J. (2009). Application of the spacing effect to improve learning and memory for functional tasks in traumatic brain injury: A pilot study. American Journal of Occupational Therapy, 63(5), 543-548. doi: 10.5014/ajot.63.5.543

Goverover, Y., Hillary, F.G., Chiaravalloti, N., Arango-Lasprilla, J. C., \& DeLuca, J. (2009). A functional application of the spacing effect to improve learning and memory in persons with multiple sclerosis. Journal of Clinical and Experimental Neuropsychology, 31(5), 513-522. doi: 10.1080/13803390802287042

Green, J., Weston, T., Wiseheart, M., \& Rosenbaum, R. (2014). Long-term spacing effect benefits in developmental amnesia: Case experiments in rehabilitation. Neuropsychology, 28, 685694. doi: 10.1037/neu0000070

Greene, R.L. (1989). Spacing effects in memory: Evidence for a two-process account. Journal of Experimental Psychology: Learning, Memory, and Cognition, 15(3), 371. http://dx.doi.org/ 10.1037/0278-7393.15.3.371

Haist, F., Shimamura, A.P., \& Squire, L.R. (1992). On the relationship between recall and recognition memory. Journal of Experimental Psychology: Learning, Memory, and Cognition, 18 (4), 691-702. http://dx.doi.org/10.1037/0278-7393.18.4.691

Heaton, R. K., Chelune, G. J., Talley, J. L., Kay, G. G., \& Curtiss, G. (1993). Wisconsin Card Sorting Test (WCST) Manual, revised and expanded. Odessa, FL: Psychological Assessment Resources.

Hurley, N. C., Maguire, E. A., \& Vargha-Khadem, F. (2011). Patient $\mathrm{HC}$ with developmental amnesia can construct future scenarios. Neuropsychologia, 49, 3620-3628. doi: 10.1016/j. neuropsychologia.2011.09.015

Kapler, I.V., Weston, T., \& Wiseheart, M. (2015). Spacing in a simulated undergraduate classroom: Long-term benefits for factual and higher-level learning. Learning and Instruction, 36, 38-45. https://doi.org/10.1016/j.learninstruc.2014.11.001

Karpicke, J.D., \& Roediger, H.L. III. (2007). Expanding retrieval practice promotes short-term retention, but equally spaced retrieval enhances long-term retention. Journal of Experimental Psychology: Learning, Memory, and Cognition, 33(4), 704. http://dx.doi.org/10.1037/0278-7393.33.4.704

Karpicke, J.D., \& Roediger, H.L. (2010). Is expanding retrieval a superior method for learning text materials? Memory \& Cognition, 38, 116-124. doi: 10.3758/MC.38.1.116

Karpicke, J.D., \& Bauernschmidt, A. (2011). Spaced retrieval: Absolute spacing enhances learning regardless of relative spacing.
Journal of Experimental Psychology: Learning, Memory, and Cognition, 37(5), 1250. http://dx.doi.org/10.1037/a0023436

Kucera, H., \& Francis, W.N. (1967). Computational analysis of present day American English. Providence, RI: Brown University Press.

Küpper-Tetzel, C.E., Kapler, I.V., \& Wiseheart, M. (2014). Contracting, equal, and expanding learning schedules: The optimal distribution of learning sessions depends on retention interval. Memory and Cognition, 42, 729-741. http://dx.doi.org/ 10.3758/s13421-014-0394-1

Lepage, M., Ghaffar, O., Nyberg, L., \& Tulving, E. (2000). Prefrontal cortex and episodic memory retrieval mode. Proceedings of the National Academy of Sciences of the United States of America, 97(1), 506-511. https://doi.org/10.1073/ pnas.97.1.506

Logan, J.M., \& Balota, D.A. (2008). Expanded vs. equal interval spaced retrieval practice: Exploring different schedules of spacing and retention interval in younger and older adults. Aging, Neuropsychology, and Cognition, 15(3), 257-280. http://doi. org/10.1080/13825580701322171

Maddox, G.B., Balota, D.A., Coane, J.H., \& Duchek, J.M. (2011). The role of forgetting rate in producing a benefit of expanded over equal spaced retrieval in young and older adults. Psychology and Aging, 26, 661-670. doi: 10.1037/a0022942

Maguire, E.A., Vargha-Khadem, F., \& Mishkin, M. (2001). The effects of bilateral hippocampal damage on fMRI regional activations and interactions during memory retrieval. Brain, 124 (6), 1156-1170. https://doi.org/10.1093/brain/124.6.1156

McAndrews, M.P., \& Milner, B. (1991). The frontal cortex and memory for temporal order. Neuropsychologia, 29, 849-859. doi: 10.1016/0028-3932(91)90051-9

Meyers, J. E., \& Meyers, K. R. (1996). Rey Complex Figure Test and Recognition Trial: Supplemental Norms for Children and Adolescents. Florida: PAR.

Milner, B., Petrides, M., \& Smith, M.L. (1985). Frontal lobes and the temporal organization of memory. Human Neurobiology, 4 (3), 137-142.

Moscovitch, M. (1992). Memory and working-with-memory: A component process model based on modules and central systems. Journal of Cognitive Neuroscience, 4, 257-267. doi: 10.1162/ jocn.1992.4.3.257

Moscovitch, M., \& Melo, B. (1997). Strategic retrieval and the frontal lobes: Evidence from confabulation and amnesia. Neuropsychologia, 35(7), 1017-1034. https://doi.org/10.1016/ S0028-3932(97)00028-6

Moscovitch, M., \& Winocur, G. (1992). The neuropsychology of memory and aging. In F.I.M. Craik \& T.A. Salthouse (Eds.), The handbook of aging and cognition (pp. 315-372). Hillsdale, NJ: Lawrence Erlbaum Associates, Inc.

Moscovitch, M., \& Winocur, G. (2002). The frontal cortex and working with memory. In D. T. Stuss \& R. T. Knight (Eds.), Principles of frontal lobe function (pp. 188-209). New York, NY, US: Oxford University Press.

Nakata, T. (2015). Effects of expanding and equal spacing on second language vocabulary learning: Does gradually increasing spacing increase vocabulary learning? Studies in Second Language Acquisition, 37(4), 677-711. https://doi.org/10.1017/ S0272263114000825

Olsen, R.K., Palombo, D.J., Rabin, J.S., Levine, B., Ryan, J.D., \& Rosenbaum, R.S. (2013). Volumetric analysis of medial temporal lobe subregions in developmental amnesia using high-resolution 
magnetic resonance imaging. Hippocampus, 23(10), 855-860. http://doi.org/10.1002/hipo.22153

Pashler, H., Bain, P., Bottge, B., Graesser, A., Koedinger, K., McDaniel, M., ... Metcalfe, J. (2007). Organizing instruction and study to improve student learning (NCER 2007-2004). Washington, DC: National Center for Education Research, Institute of Education Sciences, U.S. Department of Education.

Rabin, J. S., Braverman, A., Gilboa, A., Stuss, D. T. \& Rosenbaum, R. S. (2012). Theory of mind development can withstand compromised episodic memory development. Neuropsychologia, 50, 3781-3785. DOI: 10.1016/j.neuropsychologia.2012.10.016

Rabin, J.S., Olsen, R.K., Gilboa, A., Buchsbaum, B.R., \& Rosenbaum, R.S. (2016). Using fMRI to understand event construction in developmental amnesia. Neuropsychologia, 90, 261-273. https:// doi.org/10.1016/j.neuropsychologia.2016.07.036

Raaijmakers, J.G.W. (2003). Spacing and repetition effects in human memory: Application of the SAM model. Cognitive Science, 27, 431-452. https://doi.org/10.1016/S0364-0213(03) 00007-7

Rosenbaum, R.S., Carson, N., Abraham, N., Bowles, B., Kwan, D., Köhler, S., ... Richards, B. (2011). Impaired event memory and recollection in a case of developmental amnesia. Neurocase, 17 (5), 394-409. doi: 10.1080/13554794.2010.532138

Rosenbaum, R.S., Gao, F., Honjo, K., Raybaud, C., Olsen, R.K., Palombo, D.J., ... Black, S.E. (2014). Congenital absence of the mammillary bodies: A novel finding in a well-studied case of developmental amnesia. Neuropsychologia, 65, 82-87. doi: 10.1016/j.neuropsychologia.2014.09.047

Rosenbaum, R.S., Gilboa, A., \& Moscovitch, M. (2014). Case studies continue to illuminate the cognitive neuroscience of memory. The year in cognitive neuroscience. Annals of the New York Academy of Sciences, 1316, 105-133. https://doi.org/ 10.1111 /nyas. 12467

Rovee-Collier, C. (1995). Time windows in cognitive development. Developmental Psychology, 31(2), 147-69.

Rovee-Collier, C., Hayne, H., \& Colombo, M. (2000). The development of implicit and explicit memory, (Vol. 24). Amsterdam/Philadelphia, PA: John Benjamins Publishing.

Rugg, M.D., \& Wilding, E.L. (2000). Retrieval processing and episodic memory. Trends in Cognitive Science, 4(3), 108-115. doi:https://doi.org/10.1016/S1364-6613(00)01445-5

Shaughnessy, J., Zimmerman, J., \& Underwood, B. (1972). Further evidence on the MP- DP effect in free-recall learning. Journal of Verbal Learning and Verbal Behavior, 11(1), 1-12. https://doi. org/10.1016/S0022-5371(72)80053-7

Sobel, H.S., Cepeda, N.J., \& Kapler, I.V. (2011). Spacing effects in real-world classroom vocabulary learning. Applied Cognitive Psychology, 25(5), 763-767. doi: 10.1002/acp.1747

Sohlberg, M.M., Ehlhardt, L., \& Kennedy, M. (2005). Instructional techniques in cognitive rehabilitation: A preliminary report.
Seminars in Speech and Language, 26(4), 268-279. doi: 10.1055/s-2005-922105

Spreen, O., \& Strauss, E. (1998). A compendium of neuropsychological tests: Administration, norms, and commentary (2nd ed.). New York, NY: Oxford University Press.

Thios, S.J., \& D'Agostino, P.R. (1976). Effects of repetition as a function of study-phase retrieval. Journal of Verbal Learning \& Verbal Behavior, 15(5), 529-536. http://dx.doi.org/10.1016/0022-5371(76)90047-5

Toppino, T. C., \& Gerbier, E. (2014). About practice: repetition, spacing, and abstraction. The Psychology of Learning and Motivation, 60, 113-189. DOI: 10.1016/B978-0-12-8000908.00004-4

Tsivilis, D., Vann, S.D., Denby, C., Roberts, N., Mayes, A.R., Montaldi, D., ... Aggleton, J.P. (2008). A disproportionate role for the fornix and mammillary bodies in recall versus recognition memory. Nature Neuroscience, 11(7), 834-842. doi: 10.1038/ nn.2149

Tombaugh, T. N., Kozak, J., \& Rees, L. (1996). Normative data for the Controlled Oral Word Association Test. Personal Communication. In O. Spreen \& E. Strauss (Eds.). A compendium of neuropsychological tests, second edition: Administration, norms, and commentary. New York, NY: Oxford University Press.

Tulving, E., \& Thomson, D.M. (1971). Retrieval processes in recognition memory: Effects of associative context. Journal of Experimental Psychology, 87(1), 116-124. http://dx.doi.org/10.1037/h0030186

Tulving, E., \& Thomson, D.M. (1973). Encoding specificity and retrieval processes in episodic memory. Psychological Review, 80 (5), 352-373. http://dx.doi.org/10.1037/h0020071

Vargha-Khadem, F., Gadian, D.G., Watkins, K.E., Connelly, A., Van Paesschen, W., \& Mishkin, M. (1997). Differential effects of early hippocampal pathology on episodic and semantic memory. Science, 277(5324), 376-380. doi: 10.1126/science.277.5324.376

Vargha-Khadem, F., Salmond, C., Friston, K., Gadian, D., \& Mishkin, M. (2003). Developmental amnesia: Effect of age at injury. Proceedings of the National Academy of Sciences of the United States of America, 100(17), 10055-10060. doi: 10.1073/ pnas. 1233756100

Vilberg, K.L., \& Davachi, L. (2013). Perirhinal-hippocampal connectivity during reactivation is a marker for object-based memory consolidation. Neuron, 79(6), 1232-1242. doi: 10.1016/ j.neuron.2013.07.013

Wagner, A. D., Koutstaal, W., Maril, A., Schacter, D. L., \& Buckner, R. L. (2000). Task-specific repetition priming in left inferior prefrontal cortex. Cerebral Cortex, 10(12), 1176-1184. http://dx.doi.org/10.1093/cercor/10.12.1176

Xue, G., Mei, L., Chen, C., Lu, Z.L., Poldrack, R., \& Dong, Q. (2011). Spaced learning enhances subsequent recognition memory by reducing neural repetition suppression. Journal of Cognitive Neuroscience, 23(7), 1624-1633. doi: 10.1162/jocn.2010.21532 